\title{
USO DO TERRITÓRIO NO VALE DO SÃO FRANCISCO: SISTEMA TÉCNICO AGRÍCOLA DA FRUTICULTURA IRRIGADA*
}

\author{
Soraia de Fátima Ramos**
}

Resumo: O artigo sintetiza aspectos da orientação teórico-metodológica de Milton Santos com a apresentação da problemática de dissertação de mestrado, realizada no Departamento de Geografia da Universidade de São Paulo entre 1998 e 2001. O objetivo é indicar o referencial teórico que substanciou a pesquisa, a qual teve por meta investigar os novos usos do território no Submédio do Vale do São Francisco, região nordeste do Brasil. Desde meados da década de 1970, com a expansão seletiva do meio técnico científico informacional pelo país, se constitui em parcela da porção semiárida, nos municípios de Petrolina-PE e Juazeiro-BA, o sistema técnico agrícola da fruticultura irrigada de exportação. A dinâmica do território regional - objetos e ações - foi analisada à luz das modernizações e especialização da produção no campo.

Palavras-chave: uso do território, sistemas técnicos agrícolas, modernização agrícola seletiva, fruticultura irrigada em Petrolina (PE)/Juazeiro (BA).

\section{THE USE OF THE TERRITORY OF THE SÃO FRANCISCO VALLEY: AGRICULTURAL TECHNICAL SYSTEM OF IRRIGATED FRUIT FARMING}

\begin{abstract}
The article summarizes aspects of Milton Santos' theoretical and methodological guidance with the presentation of the issue of master's thesis, conducted at the Department of Geography, University of São Paulo between 1998 and 2001 . The purpose is to indicate the theoretical reference that supported the research, which aimed to investigate new uses of the territory in Submédio São Francisco Valley, northeast region of Brazil. Since mid-1970s, with the selective expansion of the technical scientific and informational milieu across the country, constitutes in part of the semi arid portion, in the municipalities of Petrolina (Pernambuco) and Juazeiro (Bahia), the agricultural technical system of irrigated fruit farming to export. The dynamics of the regional territory - objects and actions - was examined in the light of the modernization and specialization of production in field.
\end{abstract}

Keywords: Use the territory, technical agricultural systems, agricultural modernization selective, irrigated fruit in Petrolina (PE)/Juazeiro (BA).

\section{Introdução}

O artigo apresenta as ideias
norteadoras da proposta teórico-
metodológica de Milton Santos, as quais
embasaram o estudo da modernização
agrícola seletiva no contexto da segunda
metade do século XX. A aplicação da teoria
maior, de Milton Santos, conduziu a pesquisa
de mestrado à análise da realidade empírica
numa porção do Brasil. Foi o desejo de
construir uma teoria menor a partir do exame do uso agrícola do território e do aprofundamento do conceito de sistemas técnicos agrícolas como a contribuição particular da investigação.

Nos de 1990, Milton estimulava a minha curiosidade intelectual indagando-me como a Geografia deveria compreender e explicar as transformações socioespaciais em

\footnotetext{
* Este trabalho é parte da dissertação de mestrado Uso do território brasileiro e sistemas técnicos agrícolas: a fruticultura irrigada em Petrolina (PE)/Juazeiro (BA)", realizada sob orientação do Prof. Dr. Milton Santos e apresentada ao Departamento de Geografia da Universidade de São Paulo (USP) em 2002.

** Geógrafa, mestre, pesquisadora científica do Instituto de Economia Agrícola (IEA), Av. Miguel Stéfano, 3.900, São Paulo-SP, fone: (11) 5067-0592, fax (11) 5073-4062. E-mail: soraia@iea.sp.gov.br
} 
áreas com funções agrícolas: a) O que seriam e como se constituíam os usos agrícolas do território diante da globalização? b) De que modo o território exerceria um papel, facilitando ou impedindo a atividade econômica e, por outro lado, como certas atividades econômicas influenciariam as mudanças no território?

Afirmava Milton Santos que, primeiramente, era preciso compreender o conjunto do país, para daí investigar subsistemas ou subespaços, o que poderia ser feito a partir do estudo de um produto agrícola ou de uma parte do território. Milton deixou-me à vontade para definição final do objeto de estudo, que procuraria entender o espaço agrário a partir do seu grau de racionalidade instrumental, ou como assinalava, em função de densidades técnicas, científicas e informacionais.

De fato, em cada fração do território brasileiro era possível diferenciar níveis de modernizações a partir da presença das variáveis do atual período. Para Milton entre as especificidades do presente estão: a) a ideia de unicidade técnica, referindo-se ao domínio das técnicas hegemônicas; b) a convergência dos momentos, isto é, como o acontecer local se torna global em razão do avanço das técnicas da informação; c) a apropriação das conquistas técnicas pela mais valia global; d) a ideia de cognoscibilidade do planeta, como possibilidade de conhecimento real de todos os lugares do mundo (SANTOS, 1996).

Das investigações sobre a expansão da agricultura científica (SANTOS, 2000), chamou-me atenção o fato de ocorrer uma modernização seletiva da agricultura brasileira em plena região semiárida ${ }^{1}$ do Nordeste. Naquele cenário da década de 1990, eram poucas as investigações críticas a respeito do processo histórico de constituição dessa nova problemática regional. Em geral, as publicações se limitavam a indicar com bastante otimismo os números da expansão da fruticultura irrigada direcionada à exportação. Contudo, por meio dos conceitos elaborados por Milton Santos foi possível realizar uma reflexão geográfica atenta aos desiguais alcances e benefícios dessa moderna agricultura no sertão.

Assim, ao escolher a região do Submédio do Vale do São Francisco $^{2}$ pretendeu-se examinar algumas premissas inspiradas no referencial teórico de Milton Santos. Partindo-se do princípio de que o espaço geográfico configura-se como um sistema de objetos e de sistema de ações (SANTOS, 1996), buscou-se desvendar os

1 O semiárido apresenta clima quente e seco, temperatura média de $26^{\circ} \mathrm{C}, 3 \mathrm{mil}$ horas de sol/ano, entre 400 a $800 \mathrm{~mm}$ de chuva/ano, vegetação caatinga, solos rasos e pedregosos e relevo pouco movimentado (COELHO,1985). Desde 2005, segundo a SUDENE (2011), são 1.133 municípios em onze Estados do Brasil a compor a área que ficaria conhecida genericamente por sertão devido à rarefação da população. Entretanto, o São Francisco, maior rio perene que corta o semiárido até desaguar no oceano, é um diferencial a separar duas áreas distintas: a de beira-rio e a de sequeiro.

2 Segundo o Comitê da Bacia do Rio São Francisco (CBHSF, 2011), essa bacia "abrange $639.219 \mathrm{~km}^{2}$ de área de drenagem ( $7,5 \%$ do país) e vazão média de $2.850 \mathrm{~m}^{3} / \mathrm{s}$ ( $2 \%$ do do país). O rio São Francisco tem $2.700 \mathrm{~km}$ de extensão e nasce na Serra da Canastra em Minas Gerais, escoando no sentido sul-norte pela Bahia e por Pernambuco, quando altera seu curso para este, chegando ao Oceano Atlântico através da divisa entre Alagoas e Sergipe. Devido a sua extensão e aos diferentes ambientes percorridos, a bacia está dividida em quatro regiões: Alto São Francisco - das nascentes até a cidade de Pirapora $\left(111.804 \mathrm{~km}^{2}-17,5 \% \mathrm{da}\right.$ região); Médio São Francisco - de Pirapora até Remanso (339.763 $\mathrm{km}^{2}-53 \%$ da região); Submédio São Francisco - de Remanso até Paulo Afonso (155.637 $\mathrm{km}^{2}$ - 24,4\% da região); e o Baixo São Francisco - de Paulo Afonso até sua foz (32.013 $\mathrm{km}^{2}-5,1 \%$ da região)" (http://www.saofrancisco.cbh.gov.br/baciasf.aspx). 
elementos que comandam e dão novo valor aos lugares, em especial aos dois municípios limítrofes: Petrolina em Pernambuco e, Juazeiro na Bahia.

Em sua obra, Milton sugere que, a partir da década de 1970, houve a expansão do meio técnico-científico-informacional por todo país, de modo mais contínuo pela chamada região concentrada (Sul, Sudeste e partes do Centro-Oeste), mas, também, de forma pontual em outras áreas do Brasil (SANTOS; SILVEIRA, 2000). Foi o ponto de partida da dissertação de mestrado Uso do território brasileiro e sistemas técnicos agrícolas: a fruticultura irrigada em Petrolina $(P E) / J u a z e i r o(B A)$, pesquisa beneficiada por bolsa de estudos concedida pela Capes.

A opção pela área justifica-se por sua importância histórica e geográfica ao longo da formação do território brasileiro. Desde há muito tempo, Petrolina e Juazeiro, têm um destaque regional; e, na década de 1990, por seu conteúdo técnico-científico-informacional, constituíram-se em importantes exemplos de produção agrícola moderna, tendo como pilar inovações tecnológicas voltadas à produção de frutas. A distinção da área aumenta com o fato de que não faz parte da região concentrada. Daí ser possível uma visualização mais nítida da política seletiva de uso do território, a qual abriga manchas de modernizações no país.

Neste subespaço, as modernizações dependeram do poder público, sobretudo, a partir da instalação dos perímetros públicos irrigados no final da década de 1960. Desde então, o dinamismo da produção e exportação de frutas in natura colocou a área como exemplo para a inserção da região nordestina no competitivo mercado internacional. Em 2009, as cinco principais culturas irrigadas em Petrolina ainda eram: manga, uva, goiaba, coco e banana, ocupando 18 mil hectares. Em 2010, Petrolina se mantinha como o maior produtor de uvas do país, com aproximadamente 10\% da produção nacional, ultrapassando Bento Gonçalves, no Sul, e foi o município brasileiro com maior valor de produção gerado por frutíferas (IBGE, 2011).

Entretanto, como a organização do território e o próprio comando da produção vêm de fora, consideramos que esta situação promoveu a constituição de um espaço instável, distanciando-se cada vez mais de uma prática e um controle exercido no lugar, porque vulnerável às necessidades e exigências exógenas.

$\mathrm{Na}$ primeira parte, o trabalho resgatou o movimento de construção da geografia do semiárido nordestino, em particular em Petrolina e Juazeiro. $\mathrm{Na}$ segunda parte, apontou as especificidades do uso do território nessa parcela do país no período mais recente, temática deste artigo. A redação original do texto de dissertação foi revisada e adaptada para atender aos objetivos aqui propostos.

O professor acompanhou-me durante toda a trajetória, inclusive no exame de qualificação, mas infelizmente 0 seu falecimento prematuro impediu-o de estar no dia da defesa. Desde então, a teoria de Milton Santos é uma referência aos trabalhos e pesquisas que realizo, no Instituto de Economia Agrícola, sobre as dinâmicas territoriais atreladas à produção agrícola no Estado de São Paulo.

Os conceitos e as categorias de análise desenvolvidas por Milton mostram a 
sua atualidade e aplicabilidade ao exame de uma realidade em constante mutação. A pertinência de seu arcabouço teórico mostrase válida quando da compreensão das singularidades locais do espaço geográfico, como a explicação das distintas possibilidades de uso agrícola do território brasileiro nos dias atuais.

\section{O espaço geográfico e a constituição do meio técnico-científico-informacional}

A particularidade da Geografia dentre as ciências humanas na análise da constituição e funcionamento da sociedade se dá por meio da dimensão espacial. O espaço geográfico é uma das instâncias sociais capazes de revelar o movimento da sociedade, assim como as estruturas econômicas, político-jurídicas e ideológicas (SANTOS, 1985). Entendido como elemento dinâmico, reage e atua, influenciando as demais estruturas $e$, por conseguinte, a sociedade como um todo. Para o autor: "O espaço é a síntese, sempre provisória, entre o conteúdo social e as formas espaciais" (SANTOS, 1996, p. 88). A análise espacial enfoca a relação entre objetos e ações, combinando-se e condicionando-se mutuamente para alterar incessantemente a significação dos lugares (SANTOS, 1996).

A interpretação da sociedade por meio do conceito de uso do território, enquanto sinônimo de espaço geográfico (SANTOS; SILVEIRA, 2000), revela que a produção social do espaço vai tornando-se, a cada dia, muito mais impregnada pela mediação das técnicas. Daí a proposta de Milton Santos (1996) em nomear a Geografia como uma "filosofia das técnicas".
Se os atos técnicos sempre estiveram presentes nas ações humanas desde épocas longínquas, o que se tem verificado cada vez mais é a complexização e a universalização das técnicas hegemônicas, principalmente com o impulso dado pela ciência. Para Ellul (1968), com o "fenômeno técnico", o crescimento da sociedade torna-se submetido à intervenção da consciência e da razão na busca de eficácia. A generalização da técnica em escala mundial corresponde à civilização técnica.

De acordo com Pierre Gourou (1973), o objeto da Geografia é toda intervenção humana vista na paisagem. O homem é um criador de paisagens por meio do uso das técnicas. Assim, a sociedade é um tecido de técnicas, as respostas do homem às necessidades naturais, segundo as características de cada civilização. Por isso, para o autor, há paisagens distintas construídas em ambientes físicos semelhantes. As diferenças denotam os níveis técnicos de cada sociedade.

Para Santos (1996), há um caráter próprio à atual etapa da história pelo fato de a civilização tecnicista ser totalitária, isto é, as técnicas dominantes têm um grande poder de difusão e de imposição sobre outros meios, unificando o planeta. A técnica é um dado de explicação da sociedade humana, pois, enquanto fenômeno histórico permite a qualificação da materialidade e a empiricização do tempo. ${ }^{3}$ Mas, como nos alerta Santos (1996), a técnica sozinha não

\footnotetext{
${ }^{3}$ Milton Santos chama atenção para o fato de que as realizações humanas dão-se sobre uma materialidade e que estas revelam o caráter da sociedade: "As técnicas são datadas e incluem tempo, qualitativamente e quantitativamente. As técnicas são uma medida do tempo: o tempo do processo direto do trabalho, o tempo da circulação, o tempo da divisão territorial do trabalho e o tempo da cooperação" (1996, p. 45).
} 
explica nada, quem dá valor às técnicas é a sociedade. E, neste sentido, a Geografia por meio da qualificação do conceito de espaço elucida o caráter sistêmico e universal das técnicas e sua subordinação às determinações históricas da sociedade em geral.

Segundo Santos (1988), a história da transformação da natureza pelo trabalho humano, ou a produção do espaço geográfico proporcionadas pelas modernizações técnicas, pode ser dividida em três grandes períodos. De um meio natural ou pré-técnico, segue-se um meio técnico, chegando-se ao atual meio técnico-científico-informacional. Todos os lugares seguem esta tendência e recebem próteses resultantes das imbricações entre técnica, ciência e informação, os caracteres da história atual. Cabe à Geografia buscar distinguir as singularidades com que cada lugar acolhe ou dificulta a entrada dos elementos do novo período.

Sendo a difusão das modernizações seletiva, há a coexistência de técnicas mais antigas com as novas formas de fazer. Esta apropriação desigual das inovações técnicas pelos diversos atores é o resultado das escolhas políticas que incidem sobre um lugar. É deste modo que a Geografia chega à noção de situação geográfica (SANTOS, 1988; SILVEIRA, 1999), auxiliando-nos na delimitação das atividades humanas no território, ou seja, a área de ocorrência de certo número de eventos sobre uma materialidade e relações sociais preexistentes.

A constituição seletiva de um meio técnico-científico-informacional no Brasil ocorre após a Segunda Guerra Mundial intensificando-se, sobretudo, nos anos de 1970. No dizer de Milton Santos e Maria Laura Silveria, "o meio técnico-científicoinformacional é a expressão geográfica da globalização (2001, p. 28). Essa nova densidade do espaço geográfico, imbuída de objetos técnico-científicos e de ações concomitantes, permitirá mudanças no uso do território brasileiro.

No Submédio do Vale do São Francisco, por exemplo, isto ocorre com a instalação de um sistema técnico agrícola prenhe de modernizações. Torna-se viável a expansão do cultivo de frutas irrigadas na região semiárida. A teoria geográfica de Milton Santos fornece 0 instrumental conceitual para explicar o arranjo particular entre objetos e seu uso social, a cada etapa das condições socioculturais, políticas e econômicas que incidem historicamente sobre o lugar.

\section{Uma periodização para os sistemas técnicos agrícolas em Petrolina e Juazeiro}

As situações geográficas no interior da formação socioespacial brasileira (SANTOS, 1982) resultam da combinação de caracteres locais herdados com a história presente. Para explicar as transformações territoriais em Petrolina e Juazeiro, se propôs uma periodização baseada nas transformações gerais conhecidas pelo Brasil e mundo, mas que se deram de modo particular na região. No dizer de Santos (1996, p. 107): "A cada momento, cada lugar recebe determinados vetores e deixa de acolher muitos outros. É assim que se forma e mantém a sua individualidade. 
movimento do espaço é resultante deste movimento dos lugares".

O exame da área conurbada de Petrolina e Juazeiro remete à passagem de um meio natural, que dominou a região por um grande período, a um meio técnico, e a recente instalação de um meio técnico científico informacional, ainda que coexistente com antigos modos de produzir. A sucessão desses meios geográficos foi investigada sob a perspectiva histórica dos sistemas técnicos agrícolas, identificando as alterações na feição da paisagem e nas relações sociais da área.

Demarcamos para o propósito do trabalho três grandes fases e quatro subperíodos, buscando resgatar o processo histórico de constituição do espaço geográfico em Petrolina e Juazeiro:

- $1^{\text {a }}$ fase - época colonial até fins do século XIX (período pré-técnico)

- $2^{a}$ fase - fins do século XIX a meados dos anos de 1960 (período técnico):

- Subperíodos: Final do século XIX aos anos de 1940 e dos anos 1940 ao final dos anos de 1960;

- $3^{a}$ fase - dos anos de 1970 ao início do século XXI (período técnico-científico-informacional);

- Subperíodos: Dos anos de 1970 ao final dos anos de 1980 e dos anos de 1990 ao início do século XXI.

A primeira fase, que chega até os finais do século XIX, corresponde ao período em que a natureza impunha os limites à ocupação humana. Depois, com a mecanização do território no início do século
XX, ampliaram-se as formas de produção na região, observadas na afirmação de ambas as cidades no contexto regional. $E$, finalmente, a terceira fase, o período recente, origina-se da expansão do meio técnico-científico-informacional no país e da constituição do atual sistema técnico agrícola na área, alicerçado nos perímetros públicos irrigados.

As transformações socioespaciais foram investigadas a partir de rupturas com o sistema agrícola do período precedente. O maior conhecimento técnico-científico sobre as virtualidades naturais da área (clima quente e seco associado à oferta hídrica) e a introdução de técnicas exógenas de irrigação correspondeu a um novo sistema técnico agrícola apoiado totalmente em políticas públicas.

Esta parcela do Submédio do Vale do São Francisco possui elementos que a caracterizam como uma região singular. Ao lado dos investimentos em equipamentos $\mathrm{e}$ serviços essenciais à modernização da atividade agrícola, Petrolina e Juazeiro estabelecem novas relações, ultrapassando os limites dos municípios de sua área de influência, sendo cada vez mais intensas as transações comerciais com outros países. Atualmente, este subespaço está associado à noção de fluidez e instantaneidade, concentrando fluxos financeiros e populacionais.

Assim, a periodização deve ser vista como cortes no tempo permitindo-nos compreender processos e resultados, ou seja, determinadas situações geográficas (SILVEIRA, 1999). Há, também, a dialética correlação de forças, que incidem sobre uma área, com a observação de sistemas técnicos de períodos distintos convivendo juntos. As 
novas técnicas de irrigação prenhes de informação e saber científico somam-se e contrapõem-se às técnicas empíricas, próprias de uma fase em que as imposições da natureza prevaleciam sobre o trabalho humano.

Salienta-se, todavia, que os recortes temporais propostos não devem ser seguidos rigidamente. A realidade é um processo dinâmico e a periodização reflete a análise do investigador. Naquele contexto, foi apreendido o fenômeno técnico a partir da investigação das principais ações de políticas públicas e da instalação de objetos técnicos à atividade agrícola, bem como a sua organização e regulação.

\section{Os sistemas técnicos agrícolas no Submédio do Vale do São Francisco}

O estudo do espaço geográfico compreende, segundo proposições de Santos (1996), a análise de sua forma-conteúdo ou, em outras palavras, o seu sistema de objetos e sistema de ações. Desde a segunda metade do século $X X$, como resultado da divisão internacional e territorial do trabalho e difusão de novos objetos técnico-científicos, as formas geográficas de áreas agrícolas modernizadas são influenciadas por ações e interesses distantes das reais necessidades do lugar. O campo acolhe e difunde mais rápido que a cidade o capital novo, ainda que com variações no tempo e espaço. Contudo, encontra-se na cidade, na maioria das vezes distante da produção agrícola local, o comando técnico e político, regulador do trabalho e das atividades necessárias à produção (SANTOS, 1993).
A competitividade, outra marca do atual período, equivale à tendência para a instalação da agricultura científica em todo o planeta, "com a cientifização da agricultura, há a produção de um espaço geográfico mais denso em ciência, técnica e informação, respondendo às exigências de aumento de produtividade" (SANTOS, 2000). A criação desse espaço mais denso altera as possibilidades de produção permitindo, por exemplo, a introdução de certos cultivos em áreas antes inadequadas, ampliando-se as possibilidades de uso do território para a agricultura.

Daniel Faucher (1953) também destacou o papel da ciência na produção agrícola. Para este autor, cada período da história corresponde a determinadas condições de produção, impondo-se aos estudos geográficos 0 exame das transformações materiais. Para Faucher, a atenção deveria ser dada ao ritmo particular da evolução agrícola e à constituição de certos tipos de cultivo, propondo a noção de sistemas agrícolas ou sistemas de cultivo, para compreensão da singularidade das áreas produtivas e a complexidade dos fatores de produção.

Concordando com as reflexões de Faucher (1953), mas destacando o papel do fenômeno técnico para compreensão das singularidades espaciais nos modos de realizar a agricultura no presente, acreditamos que uma possível interpretação pode ser dada, então, pela investigação do que denominaremos por sistemas técnicos agrícolas. Este pode ser definido, sucintamente, como o conjunto de objetos e de ações que caracterizam o sistema de produção agrícola em um determinado lugar. 
A noção de sistemas técnicos agrícolas considera as várias dimensões do processo de produção ou, em outras palavras, os circuitos espaciais de produção e os círculos de cooperação (SANTOS, 1985). Examina desde a área, quantidade, rendimento das culturas e, por conseguinte, as pesquisas científicas e inovações tecnológicas, bem como o perfil do transporte, distribuição, comercialização e transformação do produto até o consumo final, atrelados que estão à dinâmica de mercado, do marketing; e, também, as características do trabalho, estrutura fundiária e políticas vinculadas. As ações técnicas e políticas voltadas para a produção formam um sistema, no qual cada elemento se relaciona com os demais e os influencia, alterando o seu valor individual e, também, o todo (GOLDMANN, 1979).

A introdução de uma variável em uma área modifica as relações sociais preexistentes e estabelecem outras, mudando o lugar (SANTOS, 1988, p. 99). Da produção no campo até as fases de distribuição, circulação e consumo, o estudo das variáveis, que compõe os sistemas técnicos agrícolas, indica que elas constituem um sistema porque funcionam inter-relacionadas, e as combinações daí resultantes apontam o processo histórico do desenvolvimento de regiões agrícolas singulares.

Ao investigar a configuração territorial no Submédio do Vale do São Francisco, realçamos alguns dos elementos componentes dos sistemas técnicos agrícolas próprios do período e que exprimem uma complexidade e relevância própria em Petrolina e Juazeiro: as políticas públicas, as inovações nas técnicas de irrigação, o cultivo de frutas irrigadas para exportação e os distintos fluxos de relações segundo o perfil dos diferentes agentes sociais atuantes na região.

O aperfeiçoamento nos métodos de irrigação provoca, quase sempre, uma dinamização da área útil à atividade agrícola e a introdução de novos tipos de cultivos. Pierre George (1982), diz que por meio das técnicas de irrigação o homem promoveu a atividade agrícola em áreas antes inviáveis; há, assim, o que ele chama de criação de espaço agrícola e o rompimento com as adversidades do meio natural. Já para Faucher (1953, p. 27), a irrigação, "sem transformar radicalmente o meio climático, o corrige e the confere novas possibilidades".

Em Petrolina e Juazeiro, o método mais antigo de irrigar é a inundação ou agricultura de vazante praticada pelos ribeirinhos às margens do São Francisco que, costumavam aproveitar as cheias do rio para irrigar plantações de ciclo vegetativo curto (ANDRADE, 1970, p. 100-101). Nesse período pré-técnico, a produção agrícola não podia atingir grande escala, nem os agricultores podiam escolher a melhor época para o plantio, de acordo com a demanda de mercado. A irrigação dependia totalmente das determinações da natureza, com seus períodos de cheia e estiagem.

Com o advento do período técnico e, posteriormente, o período técnico-científico-informacional, novos métodos de irrigar são introduzidos. Ao uso da roda d'água nos anos de 1940, sucederam-se o uso do motor a óleo diesel, nos anos de 1950 e, posteriormente, a eletrobomba (ANDRADE, 1970). Depois, foi adotado o sistema de pivô central e, em seguida, a aspersão 
convencional, que possibilitava irrigar uma área maior, mas desperdiçava uma grande quantidade de água e, como os métodos anteriores, também provocava a salinização dos solos.

Assim, a técnica da rega artificial tem sido constantemente aperfeiçoada com as inovações tecnológicas. Para Milton, "cada nova técnica não apenas conduz a uma nova percepção do tempo. Ela também obriga a um novo uso do tempo, a uma obediência cada vez mais estrita ao relógio, a um rigor de comportamento adaptado ao novo ritmo" (1996, p. 148). Em países como o Brasil, os altos custos para a implantação e manutenção dos equipamentos advindos com essas novas práticas de irrigar dependem, em grande medida, das políticas públicas.

Deste modo, a década de 1970 caracterizou-se pela intervenção modernizante do Estado na região Nordeste. A construção de infraestruturas - rodovias, linhas de transmissão de energia, dutos e canais para irrigação - ajudou a viabilizar a implantação dos perímetros públicos irrigados. Houve, assim, as condições para a constituição de um moderno sistema técnico agrícola na região envolvendo um novo sistema de objetos e de ações, centrado no binômio "técnicas de irrigação-políticas públicas". Esta fase situa-se no contexto da chamada modernização conservadora (GUIMARÃES, 1978), realizada com recursos públicos com base em tecnologias e experiências internacionais no pós-guerra, mas que não modificou a arcaica estrutura da propriedade e das relações de trabalho no campo.

Assinala Brito (1991) que os
incentivos para ampliar a área irrigada se desenvolveram a partir da divulgação do Programa Plurianual de Irrigação (PPI) em 1971, pelo GEIDA (Grupo Executivo para Irrigação e o Desenvolvimento Agrícola). Vários programas atuaram com o objetivo de modernizar o rural nordestino, mas sem alcançar os objetivos sociais e técnicos propostos (PALHETA, 1991). ${ }^{4}$

Uma ação de política pública que repercutiu fortemente no Vale do São Francisco foi o papel ativo da CODEVASF (Companhia de Desenvolvimento do Vale do São Francisco). ${ }^{5}$ Essa instituição pública atuou como indutora na preparação do território para a instalação de uma racionalidade instrumental. Entre as suas funções estavam: a execução de obras para irrigação, gerenciamento dos perímetros e a assistência técnica aos produtores. O objetivo era dar condições para a viabilização dos perímetros; promovendo, ao mesmo tempo, o desenvolvimento regional e solucionando questões sociais, o que, em grande parte, não aconteceu.

Em relação aos projetos públicos de irrigação, o pioneiro no Submédio do São Francisco foi Bebedouro, em 1968, localizado entre os municípios de Petrolina e de Casa Nova, na Bahia. O poder público

\footnotetext{
4 Em 1972 estabeleceu-se o Provale (Programa Especial para o Vale do São Francisco); em 1974, o Plano de Desenvolvimento Integrado do Vale do São Francisco e, também, o Polonordeste, direcionando a agricultura familiar ao processo de modernização agrícola e subordinando os pequenos produtores às agroindústrias (WILKINSON, 1986). Em 1976 tem-se o Projeto Sertanejo, com o intuito de transformar as pequenas propriedades familiares em empresas agrícolas. Em 1974, há a criação do FINOR (Fundo de Investimentos do Nordeste), pela SUDENE.

${ }^{5}$ A Codevasf é uma empresa pública vinculada ao Ministério da Integração Nacional e deriva da antiga Comissão do Vale do São Francisco (CVSF), de 1948, transformada em 1967 na Superintendência do Vale do São Francisco (Suvale) e que, em 1974, passou a se chamar Codevasf.
} 
disponibilizava a área a ser ocupada por colonos e empresas, equipando o local com toda a infraestrutura necessária à instalação dos irrigantes nos lotes: os canais e dutos para irrigação, asfaltamento, eletrificação, e as agrovilas servidas por escolas, postos médicos e moradias; além de fornecer assistência técnica rural.

O alvo inicial para ocupação dos perímetros era a população de baixa renda da área de sequeiro e dos municípios circunvizinhos (VERGOLINO; VERGOLINO, 1997), incluindo os imigrantes dos Estados do Piauí, Ceará e Maranhão, os quais irão garantir a experiência na prática da agricultura irrigada, onde o capital privado ainda não via atrativos para sua instalação. Para Guedes Pinto (1989, p. 129), "os projetos públicos de irrigação, que em geral são pioneiros nas áreas onde se instalam, têm papel relevante como indutores da iniciativa privada".

Desde a implantação dos primeiros projetos públicos de irrigação houve, também, a instalação de empresas na área. Entretanto, Cavalcante (1997) nos adverte que, apesar de as iniciativas privadas terem ocorrido, elas só foram possíveis devido ao forte apoio do poder público, sem o qual as empresas não se teriam implantado. Daí a ambiguidade destacada pelo autor quanto ao conceito de "privado" em irrigação no Nordeste, pois se restringe apenas à fase de operação.

Em consequência e exigência para o atual uso agrícola do território regional, organizaram-se um novo sistema de objetos e sistema de ações. Em 1976, há a inauguração em Petrolina do CPTSA (Centro de Pesquisas Agropecuárias do Trópico
Semiárido), uma das unidades da Embrapa. Em 1977, inaugura-se a Barragem de Sobradinho com o propósito de nivelar o rio São Francisco para navegação, alimentar a usina de Paulo Afonso e possibilitar a prática de irrigação em grande escala. A construção da barragem pela CHESF (Companhia Hidroelétrica do São Francisco) causou grande impacto na vida dos ribeirinhos acostumados a praticar a agricultura de vazante (ANDRADE, 1983, p. 41; COELHO, 1985). As enchentes ao longo do São Francisco deixavam de obedecer ao ciclo próprio da natureza, fase em que o nativo sabia quando seria o momento de retirar-se, para dar lugar a imposições humanas distantes do conhecimento da população local.

Segundo Brito (1991, p. 115), nos anos de 1980, novas ações impulsionam a irrigação pública no país e no Nordeste. Data de 1979 a Lei no 6.662 que dispôs sobre a Política Nacional de Irrigação. Em 1986, há a criação do Proni (Programa Nacional de Irrigação) e do Proine (Programa de Irrigação do Nordeste).

Os progressos técnico-científicos favoreceram, cada vez mais, a valorização do semiárido, sobretudo às margens do rio São Francisco. Naquele cenário, a expansão no cultivo de tomates na zona semiárida ganhava enorme vulto, e revelava dois fenômenos característicos do período atual: o da tendência a especialização produtiva no uso dos espaços agrícolas e a consequente fragilidade e instabilidade produtiva que advém com estas especializações.

O ápice da produção de tomates ocorreu na década de 1980, em razão das particularidades da área quanto à insolação e 
temperatura, os quais favorecem a produção de fruto com sabor mais acentuado e de coloração adequada aos padrões de mercado. Somam-se a isto, a infraestrutura de irrigação e os incentivos fiscais oferecidos pelo Governo beneficiando a instalação de empresas processadoras de tomates, do Sul e Sudeste, tais como a Etti, Cica Norte e Parmalat.

Como bem lembra Sorj (1980, p. 45), as agroindústrias contribuem para acelerar a modernização das áreas agrícolas, ao mesmo tempo em que, criam um mecanismo de dependência do produtor em face da indústria que ele abastece. As indústrias ditam os métodos de cultivo e novas tecnologias, fornecem sementes, financiam a produção e, até mesmo, monopolizam a compra dos produtos. Muitas vezes, elas tomam a decisão de também produzirem no campo, regularizando a oferta da própria matéria-prima, e passando a dominar todo o circuito de produção.

Contudo, a superoferta de tomates, com o aumento da área plantada, provocou a sua desvalorização. A produção tornou-se inviável, também, em razão de problemas fitossanitários. A partir daí, os produtores mais capitalizados diversificou sua produção em direção às tendências de mercado. Os demais produtores ficaram vulneráveis, em grandes dificuldades, e sem as condições para novos investimentos e reconversão produtiva. No tocante às agroindústrias, duas medidas adotadas pelo Governo Federal da época levaram-nas a abandonar a área: a importação da polpa de tomates do Chile e, a chamada "guerra fiscal", com a migração das agroindústrias processadoras em direção a região Centro-Oeste.
A partir daí, a região vem cultivando as frutas tropicais e de clima temperado. As condições naturais do semiárido: calor $\mathrm{e}$ ausências periódicas de chuvas, antes tidas como entraves à produção agrícola, são no atual período técnico-científco valorizadas, ainda mais devido a qualidade dos solos e a oferta hídrica. Ao mesmo tempo, outras especificidades locais como o preço da terra e oferta de mão de obra foram combinadas com a introdução de elementos exógenos, tais como o melhoramento de espécies e a organização de sistemas de engenharia voltados à modernização das práticas de irrigação, dotando a região de particularidades ímpares. Daí que Petrolina e Juazeiro passaram a cultivar frutas não originárias da região e a obter resultados melhores do que as tradicionais áreas produtoras.

\section{Sistema técnico agrícola da fruticultura irrigada: circuito espacial de produção e círculos de cooperação}

Em decorrência de avanços consideráveis na chamada ciência aplicada nos últimos tempos, e sua associação, cada vez mais intensa, com a produção (GRANGER, 1994), os espaços destinados às atividades agropecuárias tendem a apresentar um grau de artificialização como nunca antes. Com a aplicação da ciência há a reorganização da produção, diminuindo-se o tempo e a área de trabalho agrícola. Em contrapartida, há o crescimento dos volumes produzidos e dos rendimentos obtidos. O resultado é a constituição de uma esfera cada vez mais artificial, técnico-científica, substituindo o que era apenas natural, provocando alterações no valor do lugar 
diante da divisão territorial e internacional do trabalho.

No Submédio do São Francisco, à medida que o saber sobre as potencialidades e qualidades da área se manifesta, cresce o interesse sobre o local. Beneficiadas pelos equipamentos deixados pelas culturas anteriores, que segundo FAUCHER (1953, p. 15) deixam rastros na paisagem e nos costumes, as culturas "emergentes" podem inserir-se num contexto mais favorável, pois contam com a preparação do solo e a adesão às inovações. Assim, somente após a implantação de infraestrutura pelo Estado, e as ricas experiências dos colonos irrigantes em testar métodos de irrigar e os plantios mais adequados à região, é que as empresas agrícolas instalam-se nos perímetros de Petrolina e Juazeiro.

Paralelamente a informatização do território, se desenvolveu novas tecnologias de irrigação como o gotejamento e a microaspersão, mais adequados à rega de fruteiras, molhando individualmente cada pé de planta, economizando água e garantindo a qualidade dos solos. A vantagem da irrigação é a estabilidade da produção, tornado exequível a escolha e indução do período de safra, um fator de diferencial e de maior controle sobre o escoamento da produção e acesso ao mercado internacional. Para a produção de uvas, a região produz mais de duas safras ao ano e induz a colheita tendo em vista o calendário agrícola das regiões produtoras do sul do Brasil e, do exterior, que só produziam uma safra por ano.

Os novos equipamentos de irrigação trazem, também, a possibilidade de combinarem-se com o uso de fertilizantes e agrotóxicos. A fertirrigação é um exemplo do funcionamento de 'técnicas se dando em sistema' porque, para a realização de uma dada técnica se exige a sua conjugação com outras técnicas (SANTOS, 1996). Contudo, essas constantes inovações nos métodos utilizados para irrigar otimizam a área de produção agrícola para uma minoria de agricultores mais capitalizados, além de serem inadequadas sob a perspectiva ambiental.

O destacado papel de algumas áreas no comércio internacional resulta, agora, da maior densidade em ciência, técnica e informação. Como ressalta Souza (1994, p. 48), "a técnica amplificou a possibilidade de muitos lugares entrarem em circuitos produtivos jamais sonhados". É o caso de Petrolina e Juazeiro que, a partir da cientificização da agricultura, tem se especializado na produção e exportação de frutas in natura, sobretudo para o consumidor estrangeiro dos EUA, Japão e Europa.

Desde a década de 1980, há a tendência de ampliação dos mercados de alimentos frescos, especialmente frutas e legumes, em razão da desvalorização e redução nas exportações brasileiras de commodities tradicionais. As frutas tropicais encerram oportunidades em virtude do aumento da demanda mundial por produtos com baixas calorias, de fácil preparo e consumo, rico em vitaminas, sais minerais, fibras e proteínas (GRAZIANO DA SILVA, 1996). Acompanhando esta nova demanda do mercado, o Vale São Francisco já havia passado, até o início do século XXI, pelas "ondas" do melão, melancia, acerola, banana, coco, manga e uva. 
A acirrada competitividade no comércio internacional de frutas frescas tem provocado, também, uma segmentação maior entre os próprios produtores de Petrolina e Juazeiro. De um lado, algumas modernas empresas agrícolas têm acompanhado as novas tendências e, para tanto, ao mesmo tempo ditam e buscam estratégias que garantam a sua diferenciação e participações crescentes. De outro lado, está a grande maioria dos produtores à mercê das políticas públicas e à espera da difusão das modernizações. Entre eles estão inúmeros agricultores familiares buscando saídas para as constantes oscilações no mercado de produtos agrícolas.

No Cadastro Frutícola da década de 1990 (CODEVASF, 1999), havia a indicação de vinte e nove tipos de frutas nos perímetros de Petrolina e Juazeiro. Apesar do grande potencial em cultivar uma enorme variedade de culturas, inclusive àquelas da própria região adaptadas às carências hídricas, houve a opção pela especialização em frutas exóticas. A Tabela 1 mostra, em relação à área plantada, a concentração em quatro culturas: uva, manga, coco, goiaba e banana.

Tabela 1 - Área plantada das culturas, segundo os perímetros irrigados, em Petrolina (PE) e Juazeiro (BA), em 1999

\begin{tabular}{|c|c|c|c|c|c|c|c|c|}
\hline \multirow[t]{3}{*}{ Cultura } & \multicolumn{8}{|c|}{ Área plantada (ha) } \\
\hline & \multicolumn{3}{|c|}{ Perímetros - PETROLINA } & \multicolumn{5}{|c|}{ Perímetros - JUAZEIRO } \\
\hline & Bebedouro & $\begin{array}{c}\text { Nilo } \\
\text { Coelho }\end{array}$ & $\begin{array}{c}s / \\
\text { perímetro }\end{array}$ & Curaçá & Mandacaru & Maniçoba & Tourão & $\begin{array}{c}\mathrm{s} / \\
\text { perímetro }\end{array}$ \\
\hline Abacate & - & 9,0 & 5,0 & - & - & - & - & - \\
\hline Acerola & 3,2 & 497,9 & 24,8 & 23,0 & - & 23,3 & - & 9,0 \\
\hline Atemoia & - & 22,2 & - & 8,8 & - & 1,6 & - & 11,1 \\
\hline Banana & 23,8 & $3.097,2$ & 127,7 & 31,4 & 1,9 & 167,1 & 49,9 & 178,8 \\
\hline Cajá & - & - & - & - & - & 0,5 & - & - \\
\hline Cajamanga & - & - & - & - & - & - & - & 0,5 \\
\hline Caju & - & 14,7 & - & - & - & 1,0 & - & 29,8 \\
\hline Carambola & - & 0,5 & - & - & - & 0,9 & - & 1,5 \\
\hline Coco & 31,6 & $2.081,9$ & 226,5 & 574,6 & 28,2 & 459,7 & 69,2 & 686,0 \\
\hline Figo & - & - & - & - & - & 0,5 & - & - \\
\hline Goiaba & 149,0 & $1.747,1$ & 61,3 & 114,6 & 39,3 & 409,9 & 56,9 & 145,2 \\
\hline Graviola & - & 24,3 & 2,4 & 0,8 & - & 3,4 & - & 3,7 \\
\hline Laranja & - & 1,5 & - & - & - & 0,4 & - & 2,8 \\
\hline Lichia & - & 10,9 & - & 1,3 & - & - & - & - \\
\hline Limão & 2,2 & 60,1 & 3,0 & 30,4 & 1,0 & 68,5 & 9,4 & 130,0 \\
\hline Mamão & 1,6 & 87,9 & 2,8 & 0,5 & - & 1,7 & 3,0 & 9,9 \\
\hline Manga & 71,5 & $3.945,9$ & 466,7 & $1.337,8$ & 77,7 & $1.111,4$ & 514,6 & $1.550,7$ \\
\hline Maracujá & 1,0 & 145,0 & 1,9 & 28,3 & 4,6 & 159,5 & 14,0 & 207,2 \\
\hline Pinha & 2,7 & 160,2 & 0,6 & 74,2 & - & 37,4 & 0,3 & 26,5 \\
\hline Pitanga & - & 3,0 & - & - & - & 1,0 & - & - \\
\hline Pupunha & - & 25,0 & - & - & - & - & - & - \\
\hline Romã & - & 0,5 & - & - & - & - & - & 2,5 \\
\hline Sapoti & - & 3,2 & - & - & - & 1,5 & - & 5,0 \\
\hline Seriguela & - & - & - & - & - & 0,5 & - & - \\
\hline Tâmara & - & 2,0 & - & - & - & - & - & - \\
\hline Tamarindo & - & - & 2,5 & - & - & - & - & 0,2 \\
\hline Tangerina & - & 13,2 & - & - & - & 6,2 & 11,6 & 0,5 \\
\hline Umbu & - & 1,5 & - & - & - & - & - & - \\
\hline Uva & 362,8 & $1.001,8$ & 238,1 & 474,5 & - & 92,0 & 55,6 & 134,1 \\
\hline Total & 649,4 & $12.956,5$ & $1.163,3$ & $2.700,2$ & 152,7 & $2.548,0$ & 784,5 & $3.135,0$ \\
\hline
\end{tabular}

Fonte: Cadastro Frutícola (CODEVASF, 1999). 
Na década de 1990, a uva e a manga eram produzidas nas propriedades mais modernas, de médios e grandes empresários; já a banana e a goiaba eram produzidas por colonos e, pequenos e médios produtores. A uva apesar de ser, juntamente com a manga, o "carro-chefe" da região, não se generalizou entre os pequenos produtores porque é exigente de tecnologia mais avançada, como as sementes melhoradas e o próprio trato na lavoura, 0 que torna maiores os investimentos. Já a banana, se por um lado não necessita de grandes investimentos enfrenta, por outro, um problema de ordem natural. Em decorrência do aumento do desmatamento da caatinga, tem crescido o impacto dos vendavais na destruição das plantações e a banana era a principal atingida. Por ser de manejo mais fácil é a cultura mais difundida entre pequenos produtores, sendo que a Embrapa desenvolvia variedades com pés de tamanho menor para atenuar o problema.

O atual circuito produtivo da fruticultura irrigada em Petrolina e Juazeiro, com os novos aportes técnico-científico-informacionais, é utilizado seletivamente. Daí que o alcance de mercado e os círculos de cooperação são diferenciados para cada agente envolvido no processo: "Os circuitos produtivos são definidos pela circulação de produtos, isto é, de matéria. Os circuitos de cooperação associam a esses fluxos de matéria outros fluxos não obrigatoriamente materiais: capital, informação, mensagens ordens" (SANTOS, 1994).

Concomitantemente às mudanças materiais na paisagem de Petrolina e Juazeiro notam-se as transformações sociais envolvendo agora novos agentes na produção local. Aos poucos, os lotes de pequenos irrigantes foram substituídos por áreas pertencentes a empresas. Um dos principais problemas ocorre com o escoamento da produção local. Os colonos sujeitavam-se aos intermediários, enquanto médios e grandes empresários tinham a possibilidade de encontrar melhores compradores para suas mercadorias. A produção dos pequenos produtores destinava-se ao mercado interno, ao passo que, os médios e grandes produtores negociavam com clientes do exterior.

As empresas agrícolas atuantes na região e com maior poder de decisão provocavam novas redes de relações contribuindo para alterar a materialidade presente, a participação na divisão territorial do trabalho, e as possibilidades de uso do espaço local. Eram elas as principais articuladoras do sistema de comercialização organizado entorno da Valexport (Associação dos Produtores e Exportadores de Hortifrutigranjeiros e Derivados do Vale do São Francisco). Esta associação engloba produtores e empresas e é um dos principais mecanismos de inserção dos produtos do Vale do São Francisco no mercado internacional de frutas.

O maior conhecimento sobre a ecologia nordestina tem-lhe garantido outra racionalidade no uso de seu território. Entretanto, aqueles que não os dominam ou estão à margem dos novos conhecimentos prenhes de modernizações sucessivas são excluídos da competição do mercado. No final da década de 1990, como reflexo da política de privatizações adotada pelo Governo Federal diante da globalização econômica, houve uma mudança na orientação para os projetos de irrigação, com a "emancipação" dos perímetros públicos. O governo continuou 
a garantir a construção de infraestrutura para viabilizar a produção agrícola irrigada, mas sem assegurar a construção e manutenção de equipamentos sociais.

Assim, alguns anos após a instalação dos perímetros públicos, a maioria dos colonos assentados não conseguiu manter-se à frente em seus empreendimentos. Dentre as explicações para essa situação geográfica estão as dificuldades de acesso ao crédito rural e assistência técnica, inviabilizando a produção agrícola dos colonos. Essa racionalidade que obriga a compra pelo produtor de certo tipo de sementes, adubos, trato no cultivo, embalagem etc., estreita as oportunidades, e somente alguns produtores conseguem acompanhar o ritmo de exigências do mercado internacional. Segundo Cavalcanti (1997, p. 84):

[...] o valor agregado aos produtos (polimentos das frutas, tipos de embalagem, rótulos são valores que ultrapassam a produção como tradicionalmente considerada) foge ao controle direto de alguns atores sociais e os deixam vulneráveis frente aos demais.

Desta maneira, o espaço se torna rígido porque não é flexível a todas as formas de capital e de modos de produzir, porque impõe a lógica dos rendimentos crescentes, da modernização constante e da atenção às variações do mercado, que só pode ser acompanhada por poucos. Daí termos sugerido, com o quadro abaixo, uma tipologia para diferenciar os tipos de empreendimentos agrícolas presentes na região, no início do século XXI.

Segundo Santos (1994, p. 128) há nos dias atuais "circuitos produtivos e fluxos cuja natureza, direção, intensidade e força variam segundo os produtos, segundo as formas produtivas, segundo a organização do espaço preexistente e os impulsos políticos". A análise da dinâmica da fruticultura irrigada em Petrolina e Juazeiro evidenciou que o uso do território não é o mesmo para os diversos agentes sociais.

O sistema de ações e de objetos políticas do poder público e das empresas, aliada a moderna produção agrícola irrigada se traduz por novas possibilidades de ocupação do semiárido nordestino. Este novo uso agrícola, contudo, está sendo aproveitado por médios e grandes empresários. Por outra parte, os agricultores familiares originários da área mais atingida pelas secas, a de sequeiro, encontram oportunidade nos perímetros apenas como assalariados; outros resistem ocupando lotes improdutivos de empresas. Destaca-se que, naquele contexto da década de 1990, pouca atenção era dada à produção agropecuária nas áreas de sequeiro.

A partir do século $\mathrm{XX}$, com as mudanças na orientação das políticas públicas do governo federal, e perfil dos programas sociais, advindas desde a posse do Presidente Lula, novas diretrizes tem sido colocadas aos perímetros irrigados. Atualmente, entre as ações no nível federal, está o controverso Projeto de Integração do Rio São Francisco com Bacias Hidrográficas do Nordeste Setentrional; o Programa Água para Todos, do Plano Brasil Sem Miséria, que prevê a construção de cisternas, pequenos sistemas de irrigação e barragens de água pluvial voltado às populações mais vulneráveis (Decreto no 7.535 de 26/07/2011) e, o Interáguas, com foco em assistência técnica, planejamento e gestão do setor água. 
Quadro 1 - Tipologia do perfil dos agentes sociais inseridos no sistema técnico agrícola da fruticultura irrigada no Submédio do Vale do São Francisco em 2001

\begin{tabular}{|c|c|c|c|c|}
\hline \multirow{2}{*}{$\begin{array}{c}\text { ASPECTOS DO } \\
\text { SISTEMA TÉCNICO } \\
\text { AGRÍCOLA }\end{array}$} & \multicolumn{4}{|c|}{ AGENTES SOCIAIS DA FRUTICULTURA IRRIGADA } \\
\hline & Colonos & $\begin{array}{l}\text { Pequenas } \\
\text { Empresas } \\
\text { Agrícolas } \\
\end{array}$ & $\begin{array}{l}\text { Médias } \\
\text { Empresas } \\
\text { Agrícolas } \\
\end{array}$ & \multirow[t]{2}{*}{$\begin{array}{c}\text { Grandes } \\
\text { Empresas } \\
\text { Agrícolas } \\
\end{array}$} \\
\hline Principais cultivos & $\begin{array}{l}\text { arroz, feijão, milho, } \\
\text { banana, goiaba e } \\
\text { coco }\end{array}$ & $\begin{array}{l}\text { banana, goiaba e } \\
\text { coco }\end{array}$ & $\begin{array}{l}\text { goiaba, coco, uva } \\
\text { e manga }\end{array}$ & \\
\hline Mão de obra & familiar & familiar e assalariada & $\begin{array}{l}\text { assalariada, com } \\
\text { alguma } \\
\text { especialização }\end{array}$ & $\begin{array}{l}\text { Assalariada } \\
\text { especializada }\end{array}$ \\
\hline $\begin{array}{l}\text { Compras de } \\
\text { insumos e } \\
\text { equipamentos }\end{array}$ & $\begin{array}{lr}\text { mercado } & \text { local } \\
\text { (escritórios } & \text { e } \\
\text { representantes } & \text { de } \\
\text { empresas) } & \\
\end{array}$ & $\begin{array}{lr}\text { mercado } & \text { local } \\
\text { (escritórios } & \text { e } \\
\text { representantes } & \text { de } \\
\text { empresas) } & \\
\end{array}$ & $\begin{array}{l}\text { mercado local ou } \\
\text { nacional }\end{array}$ & $\begin{array}{lr}\text { mercado nacional } & \text { ou } \\
\text { internacional } & \\
\text { (diretamente } & \text { com } \\
\text { grandes empresas) } & \\
\end{array}$ \\
\hline $\begin{array}{l}\text { Métodos de } \\
\text { irrigação mais } \\
\text { utilizados }\end{array}$ & $\begin{array}{lr}\text { aspersão } & \\
\text { convencional } & - \\
\text { dificuldades } & \text { para } \\
\text { adaptação a novos } \\
\text { métodos }\end{array}$ & $\begin{array}{l}\text { aspersão } \\
\text { convencional } \\
\text { gotejamento }\end{array}$ & $\begin{array}{l}\text { gotejamento } \\
\text { microaspersão }\end{array}$ & $\begin{array}{l}\text { gotejamento } \\
\text { microaspersão }\end{array}$ \\
\hline $\begin{array}{c}\text { Tipo de } \\
\text { Assistência } \\
\text { técnica rural }\end{array}$ & $\begin{array}{l}\text { são beneficiários da } \\
\text { assistência técnica } \\
\text { pública prestada } \\
\text { pela Codevasf }\end{array}$ & $\begin{array}{l}\text { Não são beneficiários } \\
\text { da assistência técnica } \\
\text { pública; } \\
\text { eventualmente } \\
\text { contratam técnicos e } \\
\text { consultorias }\end{array}$ & $\begin{array}{l}\text { possuem } \\
\text { assistência técnica } \\
\text { própria em seu } \\
\text { quadro de } \\
\text { funcionários }\end{array}$ & \begin{tabular}{lr} 
possuem & \multicolumn{2}{c}{ assistência } \\
técnica própria e \\
consultorias; participam \\
de eventos técnico- \\
científicos \\
acompanhando \\
inovações
\end{tabular} \\
\hline $\begin{array}{c}\text { Parcerias técnico- } \\
\text { científicas }\end{array}$ & $\begin{array}{l}\text { não realizam } \\
\text { parcerias; } \\
\text { dependem do poder } \\
\text { público para acesso } \\
\text { às novas tecnologias }\end{array}$ & $\begin{array}{l}\text { não realizam } \\
\text { parcerias; } \\
\text { dependem do poder } \\
\text { público para acesso } \\
\text { às novas tecnologias }\end{array}$ & $\begin{array}{l}\text { realizam parcerias } \\
\text { técnico-científicas } \\
\text { com a Embrapa }\end{array}$ & $\begin{array}{l}\text { realizam parcerias e } \\
\text { convênios } \\
\text { Embrapa; } \\
\text { Influenciam os } \\
\text { rumos das } \\
\text { pesquisas } \\
\end{array}$ \\
\hline $\begin{array}{l}\text { Armazenagem } \\
\text { (packing house) }\end{array}$ & não possuem & não possuem & $\begin{array}{ll}\text { Locação } & \text { de } \\
\text { infraestrutura } & \text { de } \\
\text { terceiros } & \\
\end{array}$ & $\begin{array}{l}\text { Dispõem de } \\
\text { infraestrutura própria; } \\
\text { locação a terceiros }\end{array}$ \\
\hline $\begin{array}{c}\text { Processo } \\
\text { de } \\
\text { Comercialização }\end{array}$ & $\begin{array}{l}\text { dependentes } \\
\text { intermediários }\end{array}$ & $\begin{array}{l}\text { dependentes } \\
\text { intermediários }\end{array}$ & $\begin{array}{l}\text { Realização de } \\
\text { negócios } \\
\text { diretamente com } \\
\text { grandes redes de } \\
\text { supermercados }\end{array}$ & $\begin{array}{l}\text { Realização de negócios } \\
\text { com grandes atacadistas } \\
\text { e redes } \\
\text { de supermercados; } \\
\text { comercializam a } \\
\text { produção de outros } \\
\text { produtores; possuem } \\
\text { escritórios em } \\
\text { diversos países }\end{array}$ \\
\hline Valexport ${ }^{(*)}$ & não são associados & associados & associados & $\begin{array}{l}\text { associados e } \\
\text { principais articuladores }\end{array}$ \\
\hline $\begin{array}{l}\text { Destino da } \\
\text { produção/ } \\
\text { mercado }\end{array}$ & $\begin{array}{l}\text { mercado interno } \\
\text { local, regional e } \\
\text { nacional }\end{array}$ & $\begin{array}{l}\text { mercado interno local, } \\
\text { regional e nacional }\end{array}$ & $\begin{array}{l}\text { mercado interno } \\
\text { regional e nacional }\end{array}$ & mercado externo \\
\hline
\end{tabular}

Fonte: Elaborado pela autora com base em dados da pesquisa (2001).

(*) VALEXPORT (Ass. dos Prods. e Exps. de Hortifrutigranjeiros e Derivados do Vale do S. Francisco).

Dados recentes apontam que 0 Governo Federal, por meio do Ministério da Integração Nacional, pretende ampliar a área irrigada do país em 200 mil hectares, além de projetar novos investimentos nas áreas irrigadas antigas, como forma de revitalizar os perímetros que haviam perdido grande parte de suas características de área rural. Dessa vez, o foco social e de desenvolvimento regional se dá sob a ótica de modelos de gestão sustentáveis inovadores (Boletim Regional, Informativo da Política Nacional de Desenvolvimento Regional, no 12, 2010-2011). 


\section{Considerações finais}

Ao investigar os usos agrícolas do território no período técnico-científicoinformacional, pretendíamos contribuir com uma interpretação geográfica sobre as transformações ocorridas no meio rural, enfocando as seletividades espaciais decorrentes de uma modernização agrícola excludente, ainda que impactando todo o território nacional. Partindo do referencial teórico de Milton Santos oferecemos a noção de sistemas técnicos agrícolas como suporte conceitual à compreensão do conjunto das variáveis do processo de produção agrícola (produção, circulação, distribuição e consumo) e que exprimem uma situação geográfica.

Com a ideia de sistemas técnicos agrícolas, sugerimos a possibilidade de investigar e correlacionar, os inúmeros aspectos ligados às condições de produção relacionando, por exemplo, o perfil dos agentes sociais presentes, a estrutura fundiária e as políticas vinculadas com as características da área, quantidade e rendimento das culturas. Estas, por sua vez, estão vinculadas às tecnologias de produção (melhoramento de sementes, mecanização da colheita, equipamentos de irrigação e drenagem, uso de fertilizantes, herbicidas e inseticidas, entre outros); bem como com as especificidades de transformação do produto, armazenagem, transporte, distribuição, comercialização e consumo.

A análise dos sistemas técnicos agrícolas no Vale do São Francisco serviu de fio condutor ao exame da dinâmica do uso agrícola do território em Petrolina (Pernambuco) e Juazeiro (Bahia). Buscou indicar as influências exercidas pelo espaço geográfico para o desenvolvimento da atual atividade econômica (fruticultura irrigada) e, por outro lado, identificando as ações determinantes para a realização deste novo arranjo socioespacial (políticas públicas).

A periodização nos remeteu à gênese dos processos de conformação de uma região agrícola singular em meio à zona semiárida, ajudando-nos na qualificação dos subespaços agrícolas no período atual. Os aspectos naturais, como o clima quente e seco associado à proximidade e ao aproveitamento das águas do rio São Francisco, explicam em parte as razões desta mancha de modernidade no sertão nordestino. O atual dinamismo econômico originou-se a partir da instalação de objetos técnico-científicos efeito de políticas públicas. Daí a importância da atuação da Sudene, Codevasf e Embrapa, que impulsionaram o conhecimento sobre a região e dotaram-na de infraestrutura material e política favorável à sua exploração.

Enquanto o conhecimento científico voltado para o aproveitamento econômico do semiárido não havia prosperado, ocorreram poucas modificações geográficas em Petrolina e Juazeiro, pois a área era pouco valorizada pelo capital privado. Assim, o vetor das modernizações no Vale do São Francisco se deu com a criação dos perímetros irrigados, os quais acenavam ao desenvolvimento socioeconômico, geração de emprego e melhores condições para a população local. Entretanto, na maioria das vezes, houve o acirramento dos contrastes sociais.

Por outra parte, o exame dos circuitos produtivos e os círculos de cooperação presentes auxiliaram a definir a partir de que momento há uma nova configuração territorial. Os acréscimos 
técnicos materiais e imateriais, como a ampliação do aeroporto e expansão da malha rodoviária, somado ao fato do Mercado Produtor de Juazeiro se consolidar entre os cinco maiores entrepostos comerciais do país, contribuíram para a maior fluidez do território, atraindo empresas para a produção agrícola local. Essas estabelecem novas relações entre a região e outros espaços nacional ou internacional.

Por sua vez, a dissociação cada vez maior das etapas do processo produtivo e a cientifização da agricultura, aumentam as especializações territoriais e, consequentemente, a reordenamento territorial da produção e as complementações entre lugares. A possibilidade que a região tem de induzir a colheita das frutas de acordo com as necessidades de mercado tem provocado uma reorganização da produção agrícola no país. Este fato garante à região um novo papel na divisão territorial do trabalho, com a especialização na produção de frutas frescas, o que vem atraindo modernas empresas agrícolas, acirrando-se o conflito com antigos agentes, os colonos irrigantes.

O sistema técnico agrícola da fruticultura irrigada favoreceu o crescimento urbano da área conurbada, entre Petrolina e Juazeiro, voltando-se ao atendimento da atividade agrícola moderna. Instalaram-se um grande número de estabelecimentos comerciais e serviços afins, como as casas de materiais e equipamentos para irrigação, de sementes, fertilizantes, adubos e agrotóxicos e, também, de material de construção. Com a modernização dos sistemas de irrigação e introdução de novas espécies de frutas há a exigência de uma mão de obra mais qualificada para o tratamento dos cultivos, e novos profissionais como técnicos, engenheiros agrônomos, administradores, consultores e especialistas em informática se fazem presentes na região.

Petrolina e Juazeiro sediam a realização anual da maior feira da América Latina para o setor frutícola, a Feira Nacional de Agricultura Irrigada, que em 2011 atingia a sua $22^{\circ}$ edição. Segundo o IBGE, desde 2006, Petrolina e Juazeiro são destaques na Produção Agrícola Municipal (PAM), em razão da fruticultura, estando entre os dez municípios brasileiros com maiores valores de produção agrícola.

No entanto, embora transpareça a imagem de uma produção agrícola homogênea, havia um espaço tenso e complexo, resultado da atuação dos distintos agentes nos circuitos espaciais de produção e nos círculos de cooperação. Poucos são aqueles que podem responder à lógica de produção e aos padrões de qualidade definidos em países distantes. O progresso técnico na região favoreceu a substituição e a introdução de cultivos, mais de acordo com as demandas do mercado internacional, que impõe o quê, onde, como e quanto produzir.

Com a "emancipação" dos perímetros, no final dos anos de 1990, os agricultores familiares ficaram mais vulneráveis às oscilações ditadas pelo mercado. Criou-se, então, uma estratificação dividindo produtores de acordo com o seu poder técnico e político. Isto pode ser observado com a análise do processo produtivo, desde a escolha da fruta a ser produzida, até o alcance de mercado, no momento da comercialização. É a nova exclusão social do período histórico presente. 
O estudo do uso agrícola do território em Petrolina e Juazeiro nos permitiu entender a complexidade e ambiguidade vivida atualmente pelo lugar, ao mesmo tempo fornecedor de virtualidades ímpares ao capital hegemônico, mas na maioria das vezes deixando escapar da sociedade local o controle e os ganhos sobre a produção, num misto de cooperação e conflito.

\section{Referências bibliográficas}

ANDRADE, M. C. Tradição e mudança: a organização do espaço rural e urbano na área de irrigação do Submédio São Francisco. Rio de Janeiro: Zahar, 1983.

. O problema agrário: perspectivas geográficas. In: Nordeste: espaço e tempo. Petrópolis: Vozes, 1970.

BRITO, M. S. O Programa Nacional de Irrigação: uma avaliação prévia dos resultados. Revista Brasileira de Geografia, Rio de Janeiro: IBGE, v. 53, n. 2., abr./jun. 1991. p. 113-125.

CAVALCANTI, J. S. B. Frutas para o mercado global. Revista de Estudos

Avançados. Dossiê Nordeste, v. 11, n. 29, São Paulo: IEA, 1997.

CBHSF. Comitê da Bacia Hidrográfica do Rio São Francisco. Minas Gerais, Belo Horizonte. Disponível em: <http://www.saofrancisco.cbh.gov.br/>. Acesso em: set. 2011.

CODEVASF. Cadastro Frutícola. Codevasf: Petrolina, 1999.

COELHO, J. As secas do Nordeste e a indústria das secas. Petrópolis: Vozes, 1985.

ELLUL, J. A técnica e o desafio do século. Rio de Janeiro: Paz e Terra, 1968.

FAUCHER, D. Geografia agrária: os tipos de cultivo. Barcelona: Omega, 1953.

GEORGE, P. Geografia rural. São Paulo: Difel, 1982.

GOLDMANN, L. Dialética e cultura. Rio de Janeiro: Paz e Terra, 1979.

GOUROU, P. Introducción a la geografía humana. Madrid: Alianza, 1984.
GRANGER, G. A ciência e as ciências. São Paulo: Editora Unesp, 1994.

GRAZIANO DA SILVA, J. A nova dinâmica da agricultura brasileira. Campinas: Unicamp, 1996.

GRECO, M. (Org.). Saber plural: o discurso fragmentário da ciência e a crise de paradigmas. São Paulo: ECA/USP/CNPq, 1994. p. 45-51.

GUEDES PINTO, L. C. Irrigação pública e irrigação privada: vantagens e limitações. BRASIL. Ministério da Irrigação (PRONI). Modernização agrícola e emprego: o caso do desenvolvimento da agricultura irrigada no brasil. Seminário internacional. Brasília, DF: Abeas/Proni, 1989.

IBGE. Instituto Brasileiro de Geografia e Estatística. Produção Agrícola Municipal, v. 37, 2010.

MINISTÉRIO DA INTEGRAÇÃO NACIONAL. Secretaria de Desenvolvimento Regional. Boletim Regional. Informativo da Política Nacional de Desenvolvimento Regional, Brasília, DF, n. 12, set./dez. 2010 e jan./abr. 2011. Disponível em: <http://www.integracao.gov.br/c/doc ument_library/get_file?uuid $=95$ a9250 8-ff3c-4def-b662ace 2 b86685eb\&groupId $=10157>$. Acesso em: dez. 2011.

PALHETA, I. G. V. As políticas de irrigação no nordeste: uma análise crítica. Revista do Depto. de Geografia, São Paulo: FFLCH, n. 5, 1991.

RAMOS, S. F. Uso do território brasileiro e sistemas técnicos agrícolas: a fruticultura irrigada em Petrolina (PE)/Juazeiro (BA). Dissertação (Mestrado em Geografia) - Faculdade de Filosofia, Letras e Ciências 
Humanas, Universidade de São Paulo, São Paulo, 2001.

SANTOS, M. Por uma outra globalização. Rio de Janeiro: Record, 2000.

A natureza do espaço: técnica e tempo, razão e emoção. São Paulo: Hucitec, 1996.

. Técnica, espaço, tempo. São Paulo: Hucitec, 1994.

. A urbanização brasileira. São Paulo: Hucitec, 1993.

Por uma geografia nova. São Paulo: Hucitec, 1986.

. Espaço e método. São Paulo: Nobel, 1985.

. Espaço e sociedade. São Paulo: Hucitec, 1982.

\section{Metamorfose do espaço}

habitado. São Paulo: Hucitec, 1988.

; SILVEIRA, M. L. (Orgs.). O Brasil: território e sociedade no início do século XXI. Rio de Janeiro: Record, 2001.
SILVEIRA, M. L. uma situação geográfica: do método à metodologia. Território, ano IV, n. 6, jan./jun. 1999.

SORJ, B. Estado e classes sociais na agricultura brasileira. Rio de Janeiro: Zahar, 1980.

SOUZA, M. A. A. Perversidade e globalização. MEDINA, C.; GRECO, M. (Orgs.). A globalização perversa: a fome e a pobreza, 1994. (Mimeo.)

SUDENE. Superintendência do Desenvolvimento do Nordeste. Recife: Ministério da Integração Nacional. Disponível em: $<$ www.sudene.gov.br $>$. Acesso em: set. 2011.

VERGOLINO, J. R. O.; VERGOLINO, T. B. trabalhadores sem terra na agricultura irrigada do Submédio São Francisco: índice de condições de vida. Texto para discussão n. 391. UFPE: Depto de Economia, PIMES, jun. 1997.

WIKILSON, J. O Estado, a agroindústria e a pequena produção. São Paulo: Hucitec/Salvador: Cepa-BA, 1986. 